Article

\title{
Data Commercialisation: Extracting Value from Smart Buildings
}

\author{
Antti Säynäjoki *, Lauri Pulkka, Eeva-Sofia Säynäjoki and Seppo Junnila \\ Department of Built Environment, Aalto University, P.O. Box 14100, FI-00076 Aalto, Finland; \\ lauri.pulkka@aalto.fi (L.P.); eeva-sofia.saynajoki@aalto.fi (E.-S.S.); seppo.junnila@aalto.fi (S.J.) \\ * Correspondence: antti.saynajoki@aalto.fi
}

Received: 10 August 2017; Accepted: 8 November 2017; Published: 10 November 2017

\begin{abstract}
The purpose of this paper is to explore the current state of data commercialisation and external distribution in the Finnish real estate and construction (REC) sector. We focus on how companies could more effectively benefit from digitalisation, with more holistic utilisation of data from smart buildings. We assess the current state of data utilisation and distribution using a start-up company analysis and industry workshops. According to our research, the data from smart buildings is gathered on a large scale but very seldom distributed outside company borders. The reason for this almost non-existent external data distribution is the lack of value of the external data. As a solution, we propose the Internet of Buildings framework. The framework is based on a platform ecosystem model that is complemented with data commercialisation roles. It takes into account the current data-related opportunities and challenges in the sector. Within the framework, we suggest stakeholder roles and modes of interaction that promote value creation from smart building data. The framework can be used as a starting point for developing data commercialisation and external data distribution in the sector.
\end{abstract}

Keywords: smart buildings; data commercialisation; data distribution; platforms; digital technologies; value creation; buildings services

\section{Introduction}

The ongoing digitalisation of today's society is expected to cause disruption and value shifts in several industries [1]. One of the key assets in digital business is the data that can be refined to increased value through data analysis and business transformation [2,3]. Data analysis has been named as one of the four major technology trends of this decade [4]. The term 'business intelligence' refers to "a set of technologies and processes that use data to understand and analyze business performance" [5]. It has been successfully used in many sectors to help enterprises better understand their businesses and markets and to make timely business decisions. Davenport and Harris [5] state that the utilisation of data analytics in strategic decision-making will likely lead to better business performance and competitive advantage. Big players in the information technology (IT) sector such as Google, Amazon and Facebook have developed themselves into multi-billion-euro enterprises, with business ideas, including data gathering and analysis, as major components.

The maturity model of digitalisation is presented by Iyer and Venkatraman [1]. In digitisation 1.0, firms create products and services, which are able to generate data about their users or customers in various settings. This data can be then used to remotely and conveniently modify these products or services in the future. Digitisation 2.0 is about the inter-industry distribution of the 'in-context' data gathered by smart products and services. With the exchange of this data, it is possible to fulfil customer needs with products and services across organisational boundaries. According to Iyer and Venkatraman [1], contrary to common conceptions, the real industry disruptions and value collection opportunities are actually related to digitisation 2.0 rather than 1.0. 
Digitalisation is not a new theme in the real estate and construction (REC) sector. However, studies show that the REC sector is still in the early stages of implementing digital solutions $[6,7]$. Nevertheless, the REC sector is likely among the industries that are attractive for "cross-boundary disruptors", as presented by Burgelman and Grove [8]. One relatively recent example from the literature of a company emerging from another industry into the REC sector is Google. In 2014, Google acquired Nest Labs, which was best known for its learning thermostats. With Nest as a lead device and Android as the software, Google is now reaching for the opportunities of "connected home" markets [1]. Several other companies, e.g., Apple and Amazon, which traditionally operate outside the REC sector, are also trying to grab a share of the market with their platforms and evolving ecosystems.

One example of the embodiment of digitalisation in the REC sector is smart buildings. Smart environments such as, but not limited to, smart spaces, smart homes, and smart buildings are given rather identical definitions in the academic literature. According to Cook and Das [9], a smart environment is "one that is able to acquire and apply knowledge about the environment and its inhabitants in order to improve their experience in that environment". King's [10] definition for a smart home is "a dwelling incorporating a communications network that connects the key electrical appliances and services, and allows them to be remotely controlled, monitored or accessed". Harper [11] defines smart home as "a residence equipped with computing and information technology, which anticipates and responds to the needs of the occupants, working to promote their comfort, convenience, security and entertainment through the management of technology within the home and connections to the world beyond". In this article, we use the term smart building for smart homes and all other types of buildings that encase smart spaces. Smart buildings tend to bear Internet of Things (IoT) solutions, which refers to utilising sensors, actuators, and data communication technology built into physical objects, enabling the tracking, coordination, and control of those devices across a data network or the internet [12].

Given the recent expansion of smart buildings in the REC sector, opportunities in gathering previously unreachable data regarding, for example, building conditions, indoor environments, and human behaviour in buildings are now simple matters [1]. Additionally, the rapid accumulation of big data that smart buildings enable brings along novel business opportunities that have been utilised extremely successfully and on a large scale in other industries, especially information technology $[3,4]$. Gartner, in his IT glossary, provides the definition for big data as "high-volume, high-velocity and/or high-variety information assets that demand cost-effective, innovative forms of information processing that enable enhanced insight, decision making, and process automation". According to Brock et al. [2], value from big data can be utilised either in advanced analytics by "analyzing data to solve specific business problems" or in business transformation by "leveraging data to build new business models, disrupt competitive markets and develop new revenue streams". Data gathered from buildings by, for example, various sensors and actuators fits relatively well under this definition of big data, especially on the scale of multiple buildings or even an entire national smart building stock. Although possibilities for enabling innovative insights from big data increase when moving from the single-building level towards the regional and national building stock level, all big data drawn from a smart building or buildings is referred to as 'data' throughout this article.

It is already possible to monitor, record, store, and analyse the data from smart buildings; data of conditions and user behaviour in buildings is gathered all the time [1,13-16]. Stored and properly analysed data can provide extensive knowledge of the conditions (e.g., occupancy, indoor air quality) and users (e.g., preferences, behaviour patterns) in a smart building. This knowledge may be utilised in numerous ways, for example, in optimising cleaning and waste management processes; preserving heating, cooling, and lighting energy with demand-responsive and on-demand solutions; reducing the need for an energy production marginally by predicting energy consumption from past behaviour patterns; and providing improved security and tailored health services [17-19].

Prior to drawing value from data through analysis, the data first must be gathered, distributed, and refined. Platforms have been described as technological facilitators for data value creation [3]. 
Generally, platforms are an established way of promoting innovation and co-operation among several industries, especially with high-tech businesses driven by information technology [20]. Major enterprises such as Microsoft, Apple, and Google provide hardware and software solutions for computers and other devices that serve as 'industry platforms'. Gawer and Cusumano [20] define industry platforms as "products, services, or technologies developed by one or more firms, and which serve as foundations upon which a larger number of firms can build further complementary innovations and potentially generate network effects". Network effects occur when users benefit from better offerings brought by more complementors, and an increase in users leads to demand-side economies of scale and makes the platform more attractive to complementors. Network effects are claimed to be behind the fast growth and competitive advantage of platforms across industries [21]. For some time now, platforms have been used in collecting big data, which has then been used in developing new business insights, improving core operating processes, enabling faster and better decisions, and taking advantage of changing industry value chains [2,3]. Additionally, Thomas and Leiponen [3] present platforms as an excellent way to utilise external big data in companies in data-intensive industries.

The distinction between smart buildings and platforms is important in understanding how data is commercialised in the built environment. To highlight the role of agency in the development of platforms, Gawer and Cusumano [20] juxtapose platforms with the de facto technological standards that emerge as a result of an evolutionary process. The emergent standards represent users' shared expectations for particular products and can act as industry-wide foundations, upon which firms build their own offerings. Such "dominant designs" arise in a complex process that is not planned or managed [22,23]. Smart buildings do not constitute a well-defined entity but a domain within which there are multiple complementary and conflicting technological trajectories that manifest as a variety of products, services, technologies, and standards. Platforms, on the other hand, are distinct and manageable.

This paper explores the current state of data commercialisation in the REC sector. Our research deals with how companies in the REC sector could benefit from digitalisation by utilising the novel asset of data from smart buildings. Based on the literature, we suggest that distributing the data between companies could provide them with valuable knowledge related to their clients and operating environment. Furthermore, extensive knowledge of their clients could provide them with a competitive edge in the markets. To conceptualise the untapped potential in the sector, we aim to answer to the following two research questions:

1. Does the business model of gathering and externally distributing data from smart buildings already exist in new digital business openings in the REC sector?

2. What are the challenges of external data distribution and utilisation in the REC sector, and how can they be overcome?

The empirical part of the study first concentrates on the current state of commercial data utilisation in new digital REC businesses. For that purpose, we study the business ideas of REC-related start-up companies participating in Europe's leading start-up event, Slush. After analysing the state of data utilisation, we move on to the second phase of the study. In order to understand the challenges that digital business models face in conservative mainstream REC operations, and to discuss potential solutions, we review two industry workshops that were organised for this purpose. We itemise existing and missing roles and modes of interaction in data distribution and utilisation that promote external data distribution from smart buildings. Finally, we present a tentative theoretical framework for a digitalised real estate business called the Internet of Buildings framework.

The framework is based on empirical analyses of the REC sector, as well as the literature on platforms and ecosystem theory from other industries. The term Internet of Buildings has been previously used in academia, e.g., [24,25], and industry, e.g., [26,27], to refer to diverse data from a network of smart buildings. Our focus is on the commercialisation of this data. Additionally, the term 
Internet of Buildings is apt for differentiating the framework as a business platform from physical Internet of Things products and services.

The paper is divided into five chapters. The empirical research process involving the Slush dataset and industry workshops is described in the second chapter. The results of these analyses are then presented in the third chapter. The main findings of the study and the Internet of Buildings framework are introduced and discussed in the fourth chapter. The last chapter discusses the uncertainties of the study and provides suggestions for future research.

\section{Research Process}

This exploratory study introduces and discusses a tentative theoretical framework for external data distribution in the REC sector based on the literature and qualitative analyses of empirical data. The empirical part of the study includes two phases. First, a content analysis of the descriptions of around 1600 start-up businesses was conducted. The analysis was supported with visits to company webpages for additional clarification. Second, two industry workshops were arranged, where the focus group method was utilised for data collection, and a thematic analysis of the data collected was conducted. The two research phases have different subjects and independent research materials, which are analysed separately. The results of the first phase were used in steering the second phase.

\subsection{Slush Start-Up Data}

For the first phase of the empirical part, the data was gathered during the Slush 2015 start-up and tech event, which was organised in Helsinki on 11 to 12 November 2015. Slush is an established convention, where start-up entrepreneurs can meet with investors, founders, executives, and the media. In 2015, a total of 15,000 attendees and 1700 start-ups gathered at Slush, and nearly 6000 meetings between investors and start-ups were organised. The dataset consisted of structured descriptions of 1594 international start-up companies that submitted the required information to the organisers. Originally, the material was created for the participating investors in order to provide them with information about the participating start-ups prior to the convention. In addition to the names, nationalities, business types, tracks, and industries of the start-ups, the dataset included brief descriptions of the companies themselves, their products, the current market and competition situation, and estimated growth capabilities.

Prior to the actual data analysis presented below, the Slush dataset and a few start-up interviews in the convention were used suggestively in formulating the study. The dataset was examined and used for selecting start-ups that operate in the REC sector. Those that appeared most interesting were then interviewed about the digitalisation aspects of their businesses. The semi-structured interviews provided perspective into the state of digitalisation and the current development trends in their digital business environments. The pre-examination of the dataset and the interviews steered the research into the current themes and had an important influence on the formulation of the research questions of the study.

In the actual content analysis of the Slush data, a single data reduction and the first categorisation of the reduced data were conducted simultaneously, based on whether the start-up businesses were implicitly or explicitly related to buildings. Of the 1594 start-ups examined, 196 were defined to be at least implicitly related to buildings, and thus there were selected for further analysis. Next, the reduced data was categorised based on the current markets. Of the 196 businesses somewhat related to buildings, 168 focussed on business to business (B2B), 109 on business to consumer (B2C), and 27 on business to government (B2G) markets. The figures are overlapping because a large percentage of the start-ups were found to operate in several markets. Finally, the third categorisation of the reduced data was based on the 'short description', 'company description', and 'product description' included in the original dataset. The third categorisation considered two different criteria: (a) the company is gathering data from smart buildings that could be valuable to other stakeholders and (b) the company is gathering and distributing valuable data from smart buildings. It is noteworthy that the information 
was provided by the companies themselves and that there was a limited amount of space available for the content they provided. Therefore, it is assumed that the start-ups highlighted the most relevant aspects of their companies and products in the brief descriptions. An example table of the data and analysis is presented in the Supplementary Materials (Table S1).

\subsection{Industry Workshops}

The second phase of the empirical part was organised to explain the results of the first phase and provide evidence for the development of the Internet of Buildings framework. Two industry workshops were arranged in Espoo, Finland, in the spring and summer of 2016. Altogether 37 representatives of different organisations were invited to the workshops, resulting in 25 participants in the first workshop, 21 in the second one, and 17 participants who took part in both workshops. The invited organisations were selected to represent various roles in the digitalising REC sector in Finland, including those of well-established REC companies, start-ups, and other organisations interested in the opportunities of the digitalising built environment. The start-ups that were invited to and attended the workshops were among the Slush participants analysed in the previous phase of the study. The focus group method was utilised for data collection in the workshops, and a thematic analysis of the collected data was conducted.

In the first workshop, the interviewees were first given a short introduction to the idea of external data distribution and then instructed to freely move between five stations, where they worked in groups to produce five canvases to illustrate the chains and networks of both existing and missing roles and modes of interaction in data distribution and utilisation. The canvases were not intended to systematically answer a set of questions but instead to outline what kind of data from smart buildings is already available and how it can be useful in business; who has access to data from smart buildings; who can collect, manage, or process it; who may find it useful; and, finally, what kind of co-operation between corporations could support external data distribution. Each of the five canvases was given its own theme: (1) data that can support the maintenance of buildings; (2) utilisation of data collected by building engineering systems; (3) utilisation of location and occupancy data; (4) utilisation of the building information model (BIM) in the use and maintenance phase; and (5) the creation and management of big data. The participants were advised to approach the topic in a positive way, concentrating on what already exists, as well as the possibilities. They were asked to highlight information regarding value creation and potential business benefits. The material outcome of the first workshop included these five canvases, which were then analysed. The findings were later presented to the participants for possible critique.

The second workshop was divided into two phases. In the beginning, the results of the first workshop were presented, and the participants were divided into two groups to further discuss the findings. The interviewees were asked to consider possible new roles and new modes of interaction and to generate ideas of new business models for better utilisation of digitalisation opportunities and related consumer involvement. After a short break, the participants were introduced to the theoretical concept of platform ecosystems. Two groups were formed again to discuss the possible applications of the presented theory on the REC sector, in particular as a basis for more extensive and beneficial data distribution and utilisation. In both phases, one of the groups mainly concentrated on opportunities and benefits, and the other group mainly on risks and challenges. The discussions were not intended to systematically answer a set of questions but instead to outline how consumers are encouraged to become active and what they can produce; how the data and content produced by consumers can be utilised in business; which barriers prevent this utilisation; which risks consumer involvement entails; how an ecosystem could solve the problems of external data distribution and enable new business; what might prevent an ecosystem from being formed; and which risks would need to be considered. The participants were allowed to change groups during the conversations. The discussions were recorded in written form. 


\section{Results of the Empirical Part}

The results of the empirical part that consists of the Slush start-up analysis and the industry workshops are presented in this chapter. The findings of the study are presented in the form of the Internet of Buildings framework, which is based on the synthesis of the empirical study and the literature. The framework is presented in the next chapter.

\subsection{Slush Startups}

The results of the Slush analysis, which was the first phase of the empirical part of the study, provided evidence for the first research question: Does the business model of gathering and externally distributing data from smart buildings already exist in new digital business openings in the REC sector?

The Slush analysis revealed that data gathered from smart buildings is mostly used to develop companies' own products or services and is seldom seen as a potentially valuable asset that could be sold and distributed to other companies. According to the analysis, 154 out of the identified 196 REC start-ups already gather data from smart buildings and use it in providing or developing their products or services. Of the 42 firms that do not gather data from buildings, some are companies that provide hardware such as sensors for developing smart buildings. Thus, they are not gathering data from smart buildings but rather developing products that help buildings become smart.

Despite extensive data gathering from the REC sector start-ups, only nine out of the 154 specified companies were distributing the data beyond their primary suppliers and customers as part of their business idea. According to the Slush dataset and the webpages of the companies, the firms that were distributing the data typically provided a product or service that collected the data of its surroundings or users. The data was then delivered to other service providers, who then delivered their services by utilising the distributed data. Four of these were related to security or health monitoring in smart buildings. The others were related to energy, environmental efficiency, spatial visualisation, positioning, and gardening. Six of the nine start-ups were from Europe, two from Asia, and one from North America. The results of the Slush analysis are illustrated in Figure 1.

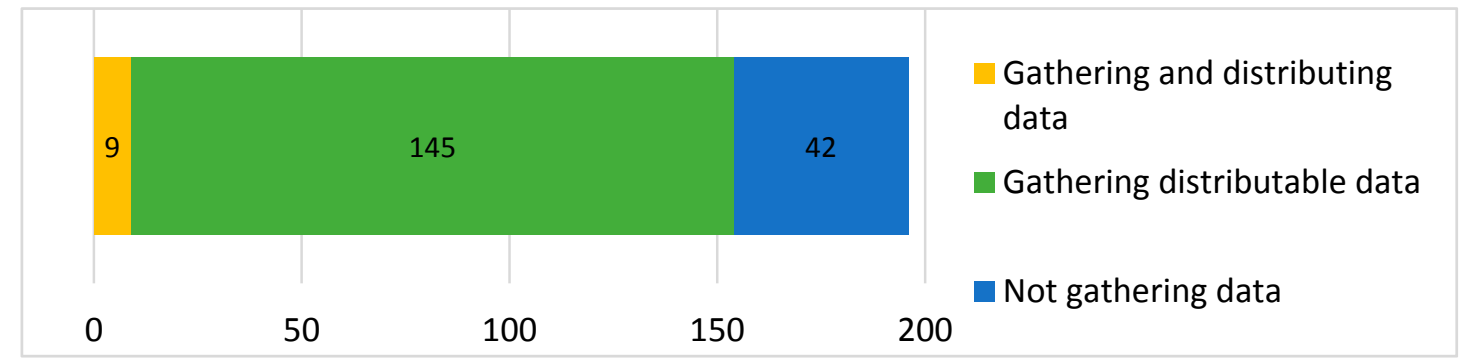

Figure 1. Data gathering and distribution patterns of the start-ups examined.

\subsection{Industry Workshops}

The second phase of the empirical part consisted of the two workshops for which the results of the Slush analysis acted as a starting point. The nature of the focus group discussions in both workshops was reinforcing rather than confronting. The topics to be discussed appeared to be quite challenging, whereupon the participants listened to each other carefully and tended to develop their own views instead of contradicting each other's opinions. Therefore, the results of the workshops mostly represent a consensus and a common understanding achieved. In the first workshop, the positive approach served the purpose as intended; deficiencies and challenges were given emphasis, but did not overwhelmingly dominate the discussions. In the second workshop, the results of the two focus groups complemented each other, and these are here presented as a single entity. Although the scope of the workshops was not limited to the research questions of this study, in the paper we only present a fraction of the relevant part of the overall results of the workshops. 
The workshops provided evidence for the second research question: What are the challenges of external data distribution and utilisation in the REC sector, and how can they be overcome? The five canvases that were produced in the first workshop to illustrate networks and modes of interaction in data distribution and utilisation revealed two interrelated findings. First, the current roles and modes of interaction that different actors were recognised to have in data distribution and utilisation were seen as insufficient. The potential for multiple businesses to benefit from external data and multiple actors to have access to data was thought to exist, but an orchestrator for distribution, referred to as a 'databank', was seen to be missing in between. Therefore, it was suggested that a databank would set the values for datasets, facilitate the trade of data, provide storage for data, and arrange the processing of data.

Second, the current transaction-based business logic in the REC sector did not appear to support the external distribution of data and new modes of networking for data distribution. There seemed to be an urgent need for a model of capturing and sharing the value of closer co-operation in data gathering and distribution. The main reason for companies not taking the role of data distributor seemed to be lack of initiative, not the potential value. However, data on location and occupancy, user preferences, indoor conditions such as temperature and air quality, and maintenance triggers were already being collected and utilised internally to improve working conditions and make maintenance more efficient. The findings were presented in the second workshop for critique but did not provoke questioning.

The transcribed discussions in the second workshop provided more detailed insights. The demand for external data was quite obvious, as the interviewees named concrete uses for the data, for example: "resource optimisation in maintenance and services through cross-border data collection and utilisation" and "as a 3D start-up, we would benefit from easily accessible additional data-it would make our operations faster and more cost-efficient". They were rather confident that the technology needed for excessively gathering data is already available. It was stated, for example, that "it is no problem to bring smart technology into old or new buildings" and that "there are already presence sensors in many places". It was brought up that especially health and security issues in buildings are already prominent business interests. Moreover, the shortening life cycles were seen to enable new solutions in modulation, portability, recyclability, and availability on order.

However, the revenue logic for data distribution was seen to be missing; for example, when it was stated that "everyone's got data and everyone wants to do business, but no-one knows how", "the data is wanted, but they are not ready to pay for it", and "data has no value if it's not being used-no-one will buy it if they don't know how to use it". The interviewees doubted if an external data distribution orchestrator's role could be economically profitable, stating, for example, "this is not platform-it doesn't make sense to do business that only spends money".

It was repeatedly mentioned in the second workshop that various real estate services are produced separately, and the companies operate in silos without significant co-operation in data gathering and distribution. For example, an interviewee said that "the sector is shattered and we live in silos". Furthermore, it was pointed out that business intelligence often has only a minor role in REC companies, and many organisations are entirely outsourcing technical functions, including information and communications technologies (ICT). Nevertheless, the brief introduction to platform ecosystems that was given to the interviewees led to a productive conversation about platform opportunities in both focus groups. It was agreed that users should have a significant role in the ecosystem, and activating the building users was seen as a positive challenge. The interviewees stated, for example, that "it is important to get users involved", "benefits have to be remarkable enough to activate use", and "adequate benefits can turn objection into excitement". Knowledge sharing between buildings and their users especially provoked active conversation. Discussions of platforms led to privacy and security issues that were seen to be critical for success in user profile services. The discussion entailed, for example, statements such as "sensitivity divides generation", "there can be strong reactions in social media", "better service can be a motive for allowing monitoring", and "data security plays 
a major role". It was highlighted that digitalised physical spaces can be highly vulnerable to data security risks: the "physical impacts of security breaches are bigger than in other sectors".

The interviewees presented two examples of readily available platform ecosystem settings. First, a regional public transport operator could provide infrastructure, data, and customers for small service providers, who would, in turn, add value to the public transport services. In the discussion, it was remarked, for example, that "we produce infrastructure and aim to increase the number of users, but it requires additional value — could be fun, convenience or comfort—for which we provide the infrastructure and a mass of customers" and that "an ideal business partner for a start-up is an established actor that has the infrastructure and produces data". Second, a regional waste management operator already provides facilities and materials for circular economy start-up companies. An interviewee explained that "we have tons of materials and good piloting facilities, and we are looking for multiple partners who have innovative ideas of using those materials". Co-operation between well-established REC companies and novel start-ups was seen to have high potential in reforming the business models.

\section{Findings and Discussion}

The purpose of this study was to find out whether the companies in the REC sector are gathering data from smart buildings and whether external data distribution is already a part of their business idea. Additionally, means to promote currently marginal data distribution and utilisation were considered.

The synthesis of the Slush and industry workshops analyses provided the answer for the first research question: Does the business model of gathering and externally distributing data from smart buildings already exist in new digital business openings in the REC sector? According to the Slush analysis, a majority (154 of 196) of building-related start-ups are gathering data and using it to complement or develop their products or services. The data is gathered, for example, from user behaviour patterns, user health, or indoor conditions, to name but a few. The large-scale data gathering indicates that the availability or costs of the technology required for gathering diverse data is not an obstacle among start-up firms, but rather a way to provide additional value to the customer. However, distribution of the data outside the companies' own use seems to be very rare, as only nine of the 154 start-ups considered commercialised external data distribution as part of their business idea. The results of the workshops support these findings. It was discussed that external data would be useful in other companies' service development, but the sector is still missing business models, as well as vital roles in external data distribution. The empirical results are also supported by the literature, suggesting that smart home services are currently developed, designed and delivered individually rather than holistically between the industries [17]. Thus, a significant share of the opportunities provided by data, which is one of the key resources of digitalised business, might be significantly unexploited in the sector. After all, external data distribution provides means for product and service development and integration beyond company and even industry boundaries, which, according to Iyer and Venkatraman [1], will cause the real disruption and value shifts of digitalisation.

According to the industry workshops, the reason for the marginal external data distribution seems to be a lack of value of the data. This issue is discussed in the context of big data commercialisation by Thomas and Leiponen [3]. In order to create value for external data distribution and use, the authors suggest that data distribution and refinement should be carried out through a platform ecosystem. Likewise, in the workshops, platforms were seen as a suitable way of gathering and distributing data. Thomas and Leiponen [3] introduce the stakeholder roles for value creation in data ecosystems that will disrupt businesses across industries. In the first workshop, the currently non-existent orchestrator of external data distribution between the companies was referred to as a 'databank'. The responsibilities of the databank can be recognised as the roles of data suppliers" and "data custodians" in the platform ecosystem roles presented by Thomas and Leiponen [3]. According to the article, it seems that the data commercialisation for feasible external data distribution requires more roles than just a single orchestrator. However, following the structure and value creation models of data ecosystems might be 
a suitable starting point in developing the roles of orchestrators and external data distribution business models in the REC sector as well.

The workshops indicate that the REC sector is currently lacking roles for the large-scale external distribution and refinement of the data between the service providers. This problem concerns both technology and business. There are currently numerous projects and other initiatives that are proposing technical solutions for collecting, distributing, and aggregating data from multiple sources. Most often, they are discussed in terms of smart building or IoT platforms. Such platforms are being developed at various levels. For example, the Intel Building Management Platform and OpenIoT both promise to enable connectivity with a variety of previously incompatible sensors and other devices that are used within properties [28,29]. Vital and CityPulse are projects aiming to create city-level frameworks that collect and analyse data from multiple sources in real-time [30,31].

Potential technical platforms already exist, and more are being developed, but the business side of the platform-equation remains unsolved. The current smart city frameworks approach the problem from the perspective of making good use of existing data that is freely available. However, based on the workshops, we argue that there are many organisations that recognise that they have valuable data but do not make it available due to a lack of incentives. In other words, external data distribution is not seen as an attractive business opportunity. Organisations are not assuming all relevant roles regarding data distribution, and the current business models in the sector do not support it.

In order to answer the second research question: What are the challenges of external data distribution and utilisation in the REC sector, and how can they be overcome? we present the Internet of Buildings framework, outlining how external data distribution can be organised to improve services and create new business in the REC sector. The framework focusses on external data distribution and utilisation, and it is based on the platform model presented by Gawer and Cusumano [20]. According to the presented literature and our empirical study, the REC sector, which has been considered to be rather conservative, is already in a data-intensive phase, meaning that data is gathered on a large scale. However, the data value creation in the sector seems to be severely inadequate as the required roles are missing and co-operation is not developed enough. Platforms have been described as technological facilitators for data value creation, as well as tools for promoting innovation and co-operation among several industries $[3,20]$. Thus, the platform-based framework was chosen as a tentative starting point of development. The framework is illustrated in Figure 2. Solid arrows denote the primary flows of non-aggregated, unrefined data and information. Dotted arrows denote the primary flows of refined data and information.

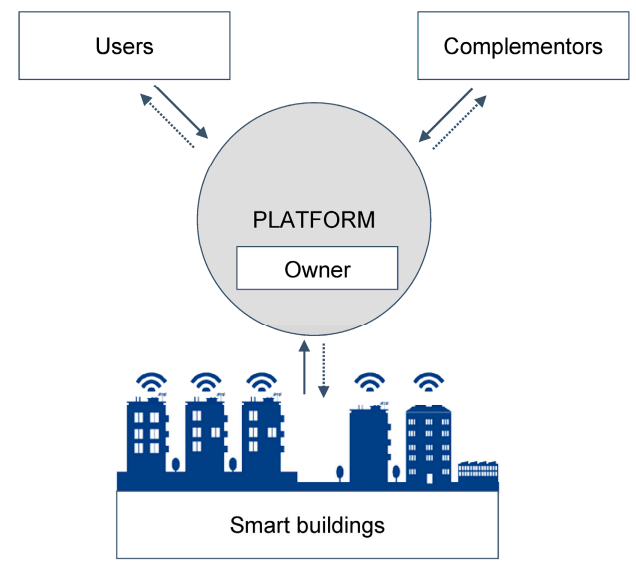

Figure 2. The platform ecosystem model for the Internet of Buildings framework (based on Gawer and Cusumano [20]).

We now describe the basic platform ecosystem roles in the framework that are based on the model of Gawer and Cusumano [20]. Then, we identify the roles of data commercialisation, within the platform ecosystem presented by Thomas and Leiponen [3] and within the framework, to enable 
data value creation. The Internet of Buildings framework combines the platform ecosystem model and the data commercialisation roles for a suggestive starting point of development for external data distribution in the REC sector.

At the centre of the framework is the platform. The platform provides the infrastructure and rules that enable and govern connections between three types of entities: users, complementors, and smart buildings. In other words, the platform is a distinct organisational actor, the owners of which have control over its governance. Depending on the platform, users can include, for example, residents, consumers, and employees. Complementors include service providers and other firms that develop complementary products and services that improve the offering of the entire platform. Users and complementors can be the same actor at different times. For example, users can also create and share their own content, contributing to the overall offering. Smart buildings refer to both physical structures and the various technologies that make them 'smart', that is, technologies that integrate buildings' subsystems and connect buildings to enable efficiency gains and new functions. Attracting many users and complementors and incorporating many smart buildings creates network effects and increases the value of the platform for all.

As industry platforms do not emerge, but are developed by one or more firms, the framework needs another type of actor: platform owners. The owner typically takes the role of the platform leader $[20,21]$. The owner is in the best position to appropriate value from the platform because he/she typically has control over membership and some critical resources or proprietary technology. However, balancing value creation at the network level and appropriation at the firm level requires care. Sometimes it is necessary to subsidise unprofitable parts to ensure the functioning and profitability of the whole system. In addition, the owner must incentivise complementors to develop complementary products and services in order to make the benefits of participation clear. Few products and technologies have the potential to be platforms. In order to fill this role, it must solve a business problem for many firms and users in the industry [20]. In the context of the REC sector, aggregating and making sense of the many individual streams of data from smart buildings is an area that has potential to benefit both firms and users.

The flows of data are explained using the six roles in big data commercialisation by Thomas and Leiponen [3]. Users, complementors, and smart buildings have the role of data suppliers. They provide unrefined raw data, visualised in Figure 2 with solid arrows. The data can be, for example, sensor-collected data on indoor air conditions, location data from users, or service frequency from complementors. One of the problems that was identified in the workshops is that, although data is extracted, there is little incentive for its distribution because the data is not considered to be valuable. In the Internet of Buildings framework, this problem is mitigated with the introduction of the platform.

The platform can take multiple roles. Its main roles are those of data custodian and data aggregator. The former means acting as a gatekeeper, controlling access to data and ensuring its quality. This role is particularly important for establishing trust and maintaining privacy. Data aggregator is responsible for the collection, aggregation and repurposing of data from multiple sources.

The platform can also have other roles, although the following are perhaps more likely to be taken up by complementors. The role of application developer means designing and building tools to analyse data. Service providers, as the name implies, provide new services based on insights from the data to customers. Data managers organise and clean information to make raw data more accessible to others. The Internet of Buildings framework, complemented with the data commercialisation roles of Thomas and Leiponen [3], is presented in Figure 3.

The technological platforms, which will be responsible for gathering and distributing the data, may be some of the existing platforms or, alternatively, completely new ones. The technical requirements of the platforms were not studied in this research. However, the existing platform types have specific advantages. The well-known platforms from the mobile device industry have already-established ecosystems. On the other hand, the IoT platforms from industrial manufacturing might be lagging behind in ecosystem participants and governance but be more robust in the sense of 
security and integration of industrial-scale machinery like building technology. The second workshop raised the concern of the requirements for the security of the platform, as security breaches of digital systems in the REC sector may result in severe consequences. For example, faulty or hijacked building controls could put the health or well-being of the building users at risk.

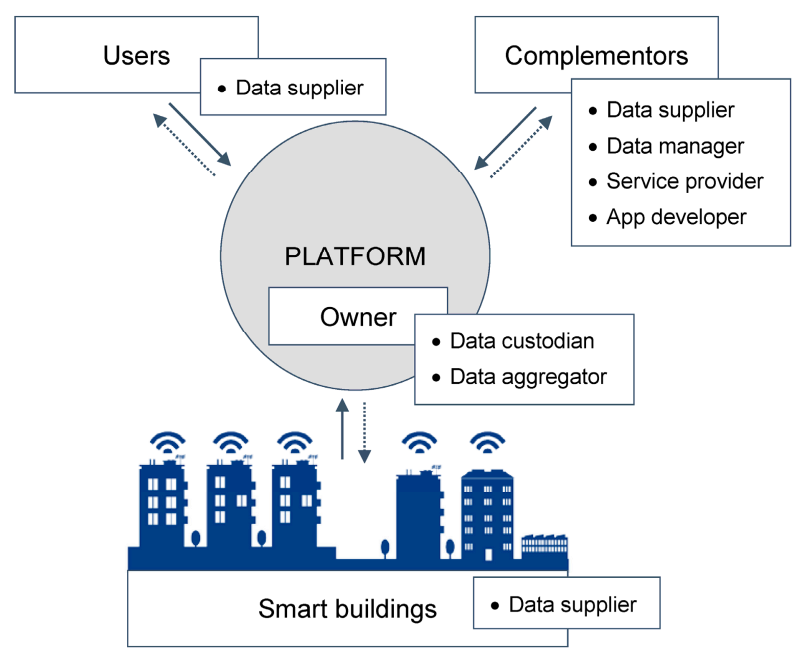

Figure 3. The Internet of Buildings framework including the roles of data commercialisation (based on Gawer and Cusumano [20] and Thomas and Leiponen [3]).

Companies in the REC sector seem to be greatly concerned that they are losing the platform race against global platform giants, that is, that they will be reduced to producers of 'dumb walls' and generic service providers fighting each other with diminishing returns on someone else's platform. However, although companies in the built environment might still be far from perfecting the recipe for turning smart technology into good business, the investments made by some of the largest global players out there have not been all that successful either. For example, Google's $\$ 3.2$ billion investment in Nest in 2014, a home automation producer, is thought to be 'underperforming', and its future under Google is considered to be at risk. Alphabet (Google's parent company), IBM, Siemens, Amazon, and other global technology companies are, of course, experimenting with various technologies and offering their solutions to public sector clients in particular, but none of them can be said to have created the definitive platform.

A possible problem for the IT giants is that they are expanding into the built environment only for the data, without understanding the operating logic and peculiarities of the sector, in order to strengthen their existing revenue models that revolve around analytics and advertisements. If this is the case, then the built environment sector companies that do understand the context and nature of the sector should not sink into pessimism but understand that they are in a better position to create value with the users. This prediction was supported by the relatively advanced ideas of platform ecosystems in the industry workshops. Furthermore, it should also be kept in mind that the platform orchestrator is not the only path to success in the digital economy. All six of the roles in big data ecosystems presented by Thomas and Leiponen [3] can be highly profitable.

There are some limitations in the study. The Slush dataset provides only a limited amount of description for each start-up, and therefore the categorisation had to be made with incomplete information of the start-ups and their products. Particularly, the description of usability of data for other stakeholders left much room for varying interpretations. Thus, it was categorised rather implicitly. Additionally, although the participants of the workshops represented the whole REC sector quite well, they still cannot be considered to accurately reflect the state of the sector. Thus, the conclusions based on the workshops are indicative rather than accurate. Furthermore, the workshop results that are relevant to this study and presented in this paper are not the main findings of the thematic analysis 
but only selected parts of it. Therefore, they are somewhat disconnected from the wider context of the discussions, which slightly compromises the focus group method.

\section{Conclusions}

The findings of the study introduce the Internet of Buildings framework, which is a tentative model for external data distribution and data commercialisation in the REC sector. The roles in the big data commercialisation ecosystems presented by Thomas and Leiponen [3] could be used as a starting point in developing the suitable data commercialisation ecosystems for the sector. External data distribution and value creation could promote improved decision making with advanced data analytics and business transformation.

However, the value creation for the data increases customer value only when the REC companies are able to develop platform-compatible business models. Current businesses in the sector cannot genuinely benefit from data from smart buildings, as they are restricted by business models that are not able to integrate data analysis into everyday processes. The Internet of Buildings framework could be used by companies to recognise the already adopted and still missing data commercialisation roles in company networks. Companies could then continue to push towards a functional data commercialisation ecosystem by developing their business models to fill all the necessary roles in the data value creation chain. Recognising the suitable roles for specific REC sector stakeholders is definitely an important area for future research in this field. Given that the scope of data commercialisation in this study was limited to the Finnish REC sector, another potential topic for future research is the divergence in the development of different countries.

Supplementary Materials: The following is available online at www.mdpi.com/2075-5309/7/4/104/s1, Table S1: An example table of the Slush data and analysis.

Acknowledgments: The authors thank Tekes—-the Finnish Funding Agency for Technology and Innovation for research funding (Grant no. 1349/31/2015).

Author Contributions: The study was conducted jointly by all the authors; All the authors participated in writing the paper.

Conflicts of Interest: The authors declare no conflicts of interest.

\section{References}

1. Iyer, B.; Venkatraman, N.V. What Comes after Smart Products. Harv. Bus. Rev. 2015. Available online: https:/ /hbr.org/2015/07/what-comes-after-smart-products (accessed on 9 August 2017).

2. Brock, J.; Dreischmeier, R.; Platt, J.; Souza, R. Opportunity Unlocked: Big Data's Five Routes to Value. BCG Perspectives: IT Advantage. 2013. Available online: https:/ /www.bcgperspectives.com/content/articles/ information_technology_strategy_digital_economy_opportunity_unlocked_big_data_five_routes_value/ (accessed on 8 July 2017).

3. Thomas, L.D.W.; Leiponen, A. Big Data Commercialization. IEEE Eng. Manag. Rev. 2016, 44, 74-90. [CrossRef]

4. Chen, H.; Chiang, R.H.L.; Storey, V.C. Business Intelligence and Analytics: From Big Data to Big Impact. MIS Q. 2012, 36, 1165-1188.

5. Davenport, T.H.; Harris, J.G. Competing on Analytics: The New Science of Winning; Harvard Business School Publishing: Boston, MA, USA, 2007.

6. Manyika, J.; Ramaswamy, S.; Kahanna, S.; Sarrazin, H.; Pinkus, H.; Sethupathy, G.; Yaffe, A. Digital America: A Tale of the Haves and Have-Mores. McKinsey \& Company, 2015. Available online: http:/ /www.mckinsey. $\mathrm{com} /$ industries/high-tech/our-insights/digital-america-a-tale-of-the-haves-and-have-mores (accessed on 8 July 2017).

7. Nölling, K. (Ed.) Think Act-Digitization in the Construction Industry; Roland Berger GmbH: Munich, Germany, 2016.

8. Burgelman, R.A.; Grove, A.S. Cross-Boundary Disruptors: Powerful Inter-Industry Entrepreneurial Change Agents. Strateg. Entrep. J. 2007, 1, 315-327. [CrossRef] 
9. Cook, D.J.; Das, S.K. How smart are our environments? An updated look at the state of the art. Pervasive Mob. Comput. 2007, 3, 53-73. [CrossRef]

10. King, N. Smart Home-A Definition. Intertek Research \& Testing Center, 2003. Available online: http:/ / www.housingcare.org/downloads/kbase/2545.pdf (accessed on 9 August 2017).

11. Harper, R. (Ed.) Inside the Smart Home; Springer-Verlag: London, UK, 2003.

12. Manyika, J.; Chui, M.; Bughin, J.; Dobbs, R.; Bisson, P.; Marrs, A. Disruptive Technologies: Advances That Will Transform Life, Business, and the Global Economy; McKinsey \& Company: New York, NY, USA, 2013. Available online: http:/ / www.mckinsey.com/business-functions/digital-mckinsey/our-insights / disruptive-technologies (accessed on 8 July 2017).

13. Chan, M.; Estève, D.; Escriba, C.; Campo, E. A review of smart homes-Present state and future challenges. Comput. Methods Programs Biomed. 2008, 91, 55-81. [CrossRef] [PubMed]

14. Chan, M.; Campo, E.; Estève, D.; Fourniols, J.-Y. Smart homes-Current features and future perspectives. Maturitas 2009, 64, 90-97. [CrossRef] [PubMed]

15. Niskanen, I. Semantic Visualization for Smart Spaces-Merging the Material and Digital Worlds (VTT SCIENCE 95); VTT Technical Research Centre of Finland Ltd.: Espoo, Finland, 2015.

16. Fensel, A.; Tomic, D.K.; Koller, A. Contributing to appliances' energy efficiency with Internet of Things, smart data and user engagement. Future Gener. Comput. Syst. 2017, 76, 329-338. [CrossRef]

17. Balta-Ozkan, N.; Davidson, B.; Bicket, M.; Whitmarsh, L. The development of smart homes market in the UK. Energy 2013, 60, 361-372. [CrossRef]

18. Ciuciu, I.G.; Meersman, R.; Dillon, T. Social network of smart-metered homes and SMEs for grid-based renewable energy exchange. In Proceedings of the 2012 6th IEEE International Conference on Digital Ecosystems Technologies (DEST), Campione d'Italia, Italy, 18-20 June 2012; pp. 1-6.

19. Tomic, S.; Fensel, A. OpenFridge: A Platform for Data Economy for Energy Efficiency Data. In Proceedings of the 2013 IEEE International Conference on Big Data, Silicon Valley, CA, USA, 6-9 October 2013; pp. $43-47$.

20. Gawer, A.; Cusumano, M.A. Industry Platforms and Ecosystem Innovation. J. Prod. Innov. Manag. 2014, 31, 417-433. [CrossRef]

21. Parker, G.G.; Van Alstyne, M.W.; Choudary, S.P. Platform Revolution: How Networked Markets Are Transforming the Economy and How to Make Them Work for You; WW Norton \& Co.: New York, NY, USA, 2016.

22. Abernathy, W.J.; Utterback, J.M. Patterns of industrial innovation. Technol. Rev. 1978, 80, 97-107.

23. Anderson, P.; Tushman, M.L. Technological Discontinuities and Dominant Designs: A Cyclical Model of Technological Change. Adm. Sci. Q. 1990, 35, 604-633. [CrossRef]

24. Virtanen, J.-P.; Kurkela, M.; Hyyppä, H.; Niemi, S.; Kalliokoski, S.; Vanhatalo, S.; Hyyppä, J.; Haggrén, H. Visualization of building models and sensor data using open 3D platforms. In Proceedings of the CIB World Building Congress 2016: Volume IV-Understanding Impacts and Functioning of Different Solutions; Tampere University of Technology, Department of Civil Engineering: Tampere, Finland, 2016; pp. 178-189.

25. McGibney, A.; Rea, S.; Ploennigs, J. Open BMS-IoT driven Architecture for the Internet of Buildings. In Proceedings of the IECON 2016-42nd Annual Conference of the IEEE Industrial Electronics Society, Florence, Italy, 23-26 October 2016; pp. 7071-7076.

26. Sinha, S.; Taparia, S. A Roadmap to the 'Internet of Buildings'. GreenBiz, 2014. Available online: https:/ / www.greenbiz.com/blog/2014/06/23/roadmap-internet-buildings (accessed on 7 November 2017).

27. Chemel, B. How Intelligent Lighting Is Ushering in the Internet of Buildings. TechCrunch, 2015. Available online: https:/ / techcrunch.com/2015/12/20/how-intelligent-lighting-is-ushering-in-the-internet-of-buildings / (accessed on 7 November 2017).

28. Intel Building Management Platform. Available online: https://www.intel.com/content/www/us/en/ smart-buildings/building-management-platform/overview.html (accessed on 23 September 2017).

29. Open IoT. Available online: http:/ / www.openiot.eu (accessed on 23 September 2017).

30. Puiu, D.; Barnaghi, P.; Toenjes, R.; Kümper, D.; Ali, M.I.; Mileo, A.; Gao, F. Citypulse: Large scale data analytics framework for smart cities. IEEE Access 2017, 4, 1086-1108. [CrossRef]

31. Vital Project Presentation. Available online: http://vital-iot.eu/project (accessed on 23 September 2017). 